\title{
CURRENT-MODE GROUNDED-CAPACITOR SINGLE-ELEMENT-CONTROLLED BANDPASS AND LOWPASS FILTERS
}

\author{
MUHAMMAD TAHER ABUELMA'ATTI \\ King Fahd University of Petroleum and Minerals, Box 203, Dhahran 31261, Saudi Arabia
}

(Received June 21, 1994; in final form July 20, 1994)

\begin{abstract}
New circuit configurations for realizing bandpass and lowpass current-mode second-order filters are proposed. Each configuration uses a single first-generation current conveyor, a transconductance amplifier, three grounded capacitors, and two resistors at most. The parameters $\omega_{0}$ and $\omega_{0} / Q_{0}$ of the bandpass and lowpass realizations are not interdependent and, therefore, single element control of the bandpass and lowpass characteristics is possible. Also, the feasibility of realizing a single element currentcontrolled sinusoidal oscillator is considered.
\end{abstract}

\section{INTRODUCTION}

In the recent past, a number of current-mode bandpass filter and lowpass filter realizations has been presented. ${ }^{(1-5)}$ None of these realizations, however, meet simultaneously the following attractive features for integration: 1 . use of grounded capacitors and 2. independent control of the parameters $\omega_{0}$ and $\omega_{0} / Q_{0}$. For example, while the circuit proposed by Chang ${ }^{(1)}$ uses two grounded capacitors, its parameters $\omega_{0}$ and $\omega_{0} / Q_{0}$ are interdependent. On the other hand, while the circuit proposed by Liu et al. ${ }^{(2)}$ enjoys independent control of the parameters $\omega_{0}$ and $\omega_{0} / \mathrm{Q}_{0}$, it uses two capacitors, at least one of them is floating. The circuit proposed by Alami et al. ${ }^{(6)}$ is, therefore, the preferred formulation as it uses two grounded capacitors and its parameters $\omega_{0}$ and $\omega_{0} / \mathrm{Q}_{0}$ are independent. However, it requires three current conveyors to take out the output current exhibiting bandpass operation. Moreover, it requires two floating resistors and it can not realize a lowpass filter.

It is, therefore, the major intention of this letter to present two new configurations. The first can realize a current-mode bandpass filter using two grounded capacitors and one floating resistor and the second can realize a lowpass filter using three grounded capacitors and two resistors, one of them grounded. In both cases, parameters $\omega_{0}$ and $\omega_{0} / \mathrm{Q}_{0}$ of the proposed bandpass and lowpass filters are not interdependent. Moreover, the feasibility of obtaining a single-element-controlled sinusoidal oscillator will be considered. 


\section{PROPOSED CIRCUIT}

Consider the circuit shown in Fig (1). Assuming ideal CCI and OTA with

$\mathrm{I}=\mathrm{g}_{\mathrm{m}}\left(\mathrm{V}^{+}-\mathrm{V}^{-}\right), \mathrm{I}_{\mathrm{x}}=\mathrm{I}_{\mathrm{y}}=\mathrm{I}_{\mathrm{z}}, \mathrm{V}_{\mathrm{x}}=\mathrm{V}_{\mathrm{y}}$

routine analysis shows that the transfer function $\mathrm{I}_{01} / \mathrm{I}_{\mathrm{i}}$ can be expressed as

$\frac{I_{01}}{I_{i}}=\frac{-s\left(1+g_{m} R\right) / C_{1} R}{s^{2}+\frac{C_{2}-C_{1}}{C_{1} C_{2} R} s+\frac{g_{m}}{C_{1} C_{2} R}}=\frac{-\alpha_{1} s}{s^{2}+\frac{\omega_{0}}{Q_{0}} s+\omega_{0}^{2}}$

Equation (1) corresponds to the transfer function of a second-order bandpass filter with $\alpha_{1}=\left(1+g_{m} R\right) / C_{1} R$, center frequency $\omega_{0}^{2}=g_{m} / C_{1} C_{2} R$, and $\omega_{0} / Q_{0}=\left(C_{2}-\right.$ $\left.C_{1}\right) / C_{1} C_{2} R$. It is obvious that the parameters $\omega_{0}$ and $\omega_{0} / Q_{0}$ are not interdependent as $\omega_{0}$ can be controlled by adjusting $g_{m}$ without affecting the parameter $\omega_{0} / Q_{0}$. Moreover, if the condition $\mathrm{C}_{1}=\mathrm{C}_{2}=\mathrm{C}$ is satisfied, the circuit can oscillate with a frequency of oscillation $\omega_{0}^{2}=\mathrm{g}_{\mathrm{m}} / \mathrm{C}^{2} \mathrm{R}$. Thus, the frequency of oscillation and the condition of oscillation are not interdependent, as the frequency of oscillation can be tuned by adjusting $g_{m}$ without affecting the condition of oscillation. And since $g_{m}$ can be adjusted by the bias current $I_{A B C}$ of the operational transconductance amplifier, then it is possible to realise a current controlled oscillator.

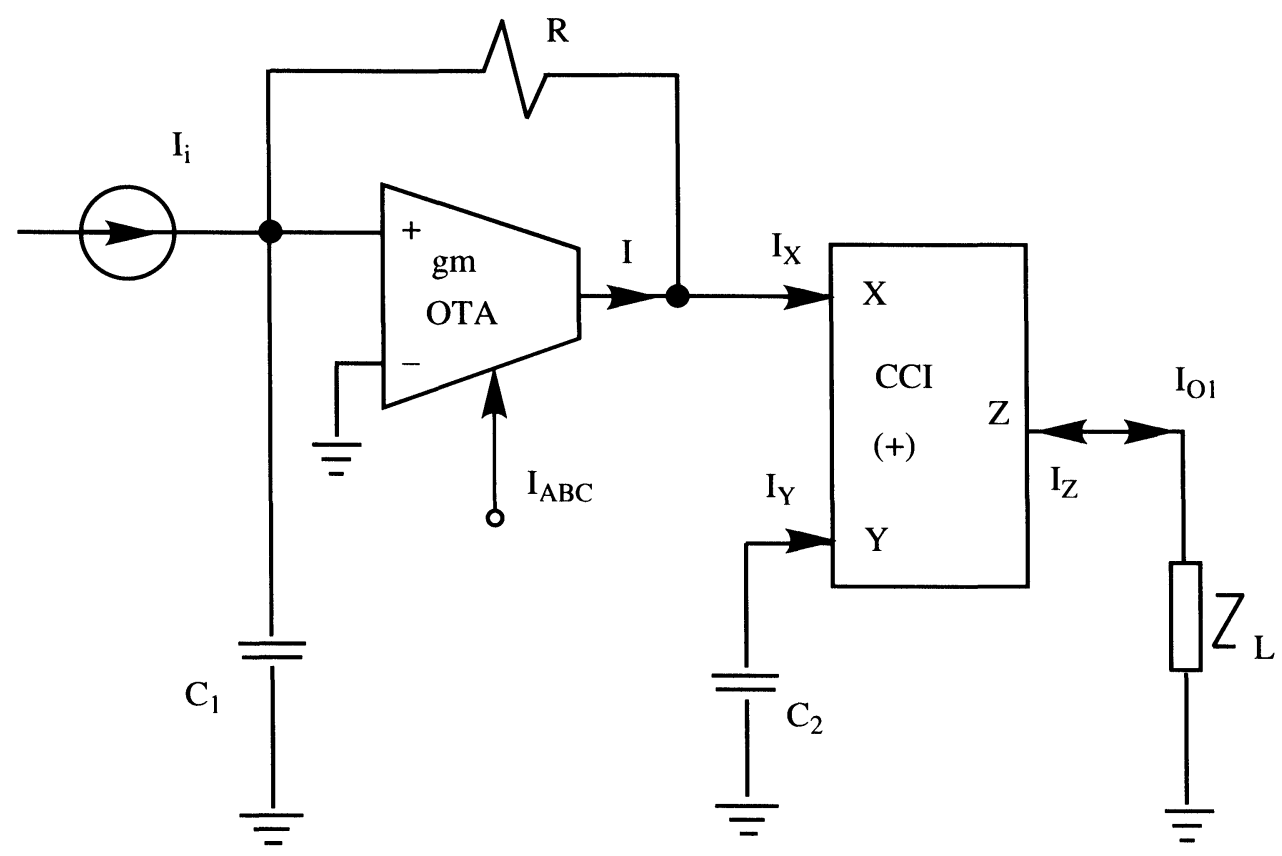

FIGURE 1 Proposed bandpass filter. 


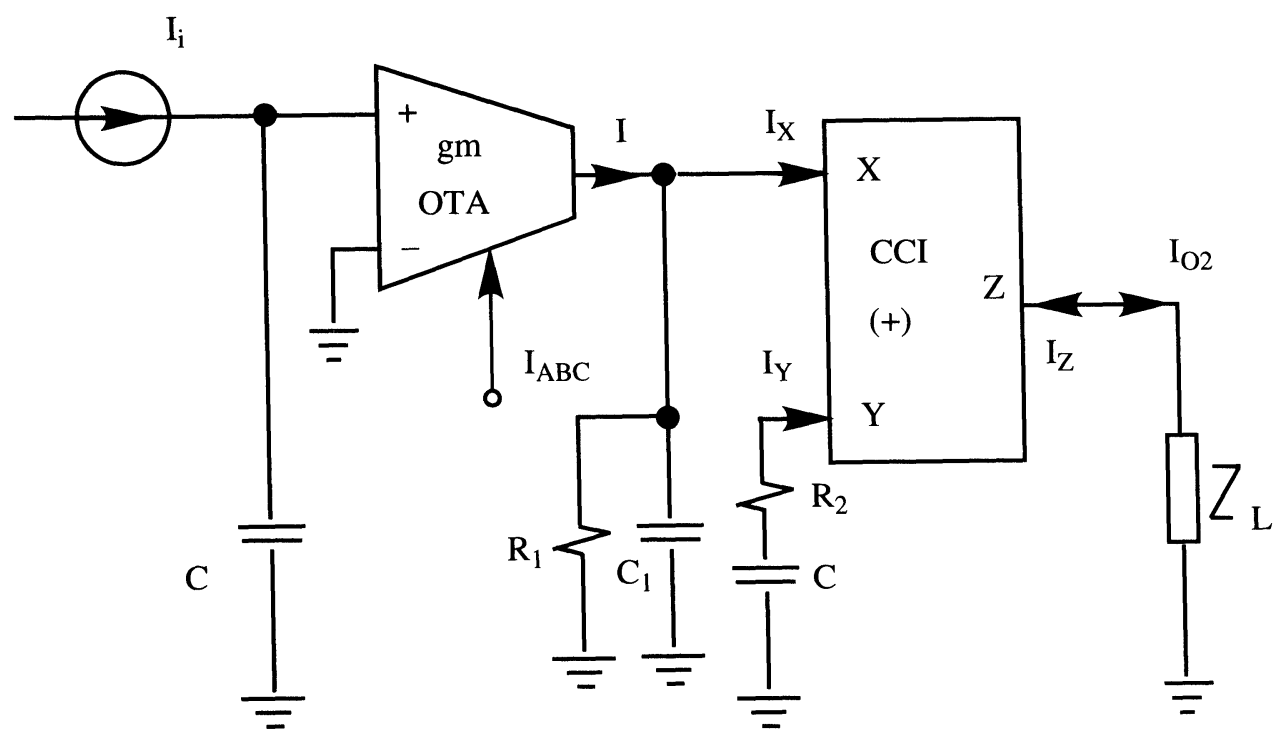

FIGURE 2 Proposed lowpass filter.

Now consider the circuit of Fig (2). Routine analysis, assuming ideal CCI and OTA shows that the transfer function $\mathrm{I}_{02} / \mathrm{I}_{\mathrm{i}}$ can be expressed as

$$
I_{02} / I_{i}=\frac{g_{m} / C_{1} R_{2}}{s^{2}+s \frac{C_{1} R_{1}+C R_{2}-C R_{1}}{C_{1} C_{1} R_{2}}+\frac{1}{C_{1} C_{1} R_{2}}}=\frac{\alpha_{2}}{s^{2}+s \frac{\omega_{0}}{Q_{0}}+\omega_{0}^{2}}
$$

Equation (2) corresponds to the transfer function of a second-order lowpass filter with $\alpha_{2}=\mathrm{g}_{\mathrm{m}} / \mathrm{CC}_{1} \mathrm{R}_{2}, \omega_{0}^{2}=1 / \mathrm{C}_{1} \mathrm{CR}_{1} \mathrm{R}_{2}$ and $\omega_{0} / \mathrm{Q}_{0}=\left(\mathrm{C}_{1} \mathrm{R}_{1}+\mathrm{CR}_{2}-\mathrm{CR}_{1}\right) /$ $C_{1} C R_{1} R_{2}$. By selecting $R_{1}=R_{2}$ (or $C_{1}=C$ ), it is easy to show that the parameters $\omega_{0}^{2}$ and $\omega_{0} / Q_{0}$ are not interdependent, that is, the parameter $\omega_{0}$ can be tuned without disturbing the parameter $\omega_{0} / \mathrm{Q}_{0}$.

\section{SIMULATION RESULTS}

The current transfer functions presented in this letter have been checked using SPICE. The current conveyor required was simulated using the circuit proposed by Heurtas, ${ }^{(8)}$ because of its simplicity, with $1 \mathrm{KOhm}$ for the current sensing resistors and $100 \mathrm{KOhm}$ and $200 \mathrm{KOhm}$ for the other resistors. Fig (3) shows the simulated and calculated transfer functions of the bandpass filter of eqn (2). From Fig (3) it is obvious that the agreement between the simulated and calculated results appears to be good. 


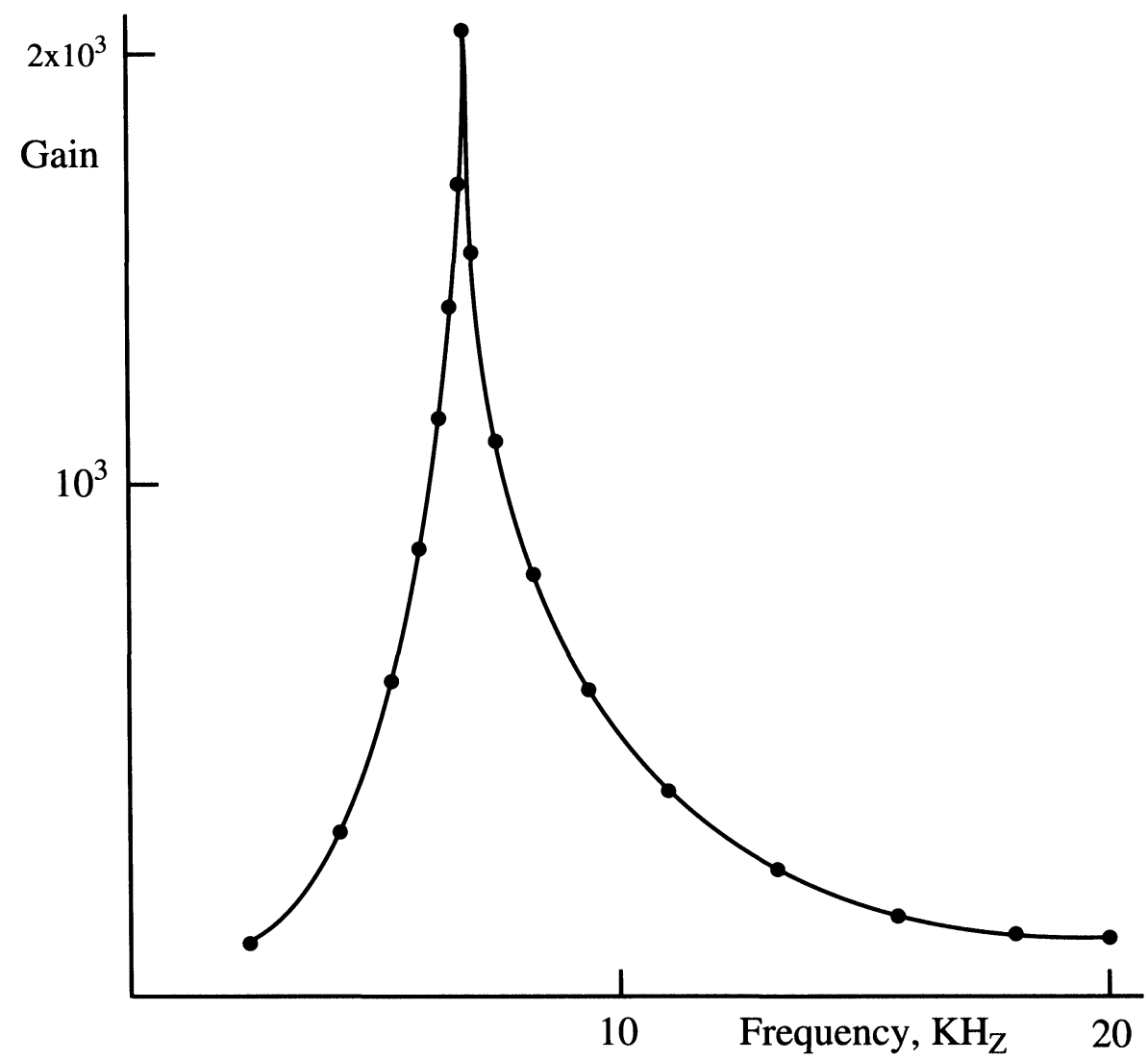

FIGURE 3 Simulated characteristics of the bandpass filter of Fig (1). $g_{m}=2 \mathrm{~mA} / \mathrm{V}, \mathrm{R}=1 \mathrm{M} \Omega, \mathrm{C}_{1}$ $=0.1 \mathrm{nF}, \mathrm{C}_{2}=10 \mathrm{nF}$.

Calculated Simulated

\section{CONCLUSION}

In this letter, new topologies for realizing current-mode bandpass and lowpass filters have been presented. In both filters, grounded capacitors are used. Also, the parameters $\omega_{0}$ and $\omega_{0} / Q_{0}$ are not interdependent. These are attractive features for integration. The feasibility of obtaining a single-element-controlled sinusoidal oscillator has been considered.

\section{REFERENCES}

1. C.-M. Chang, Current mode allpass/notch and bandpass filter using single CCII, Electronics Letters, Vol. 27, 1991, pp. 1812-1813

2. S.-I. Liu, H.-W. Tsao and J. Wu, Cascadable current-mode single CCII biquads, Electronics Letters, Vol. 26, 1990, pp. 2005-2006

3. A. Fabre, F. Martin and M. Hanaf, Current-mode allpass/notch and bandpass filters with reduced sensitivities, Electronics Letters, Vol. 26, 1990, pp. 1495-1496 
4. C.-L. Hou, Y.-P. Wu and S.-I Liu, New configuration for single-CCII first-order biquadratic currentmode filters, International Journal of Electronics, Vol. 71, 1991, pp. 637-644

5. C.-M. Chang, Universal active current filters using single second-generation current conveyor, Electronics Letters, Vol. 27, 1991, pp. 1614-1616

6. M. Alami and A. Fabre, Insensitive current-mode bandpass filter implementation from two current conveyors, Electronics Letters, Vol. 27, 1991, pp. 897-899

7. R.L. Geiger and E. Sanchez-Sinebcio, Active filter design using operational transconductance amplifiers: A tutorial, IEEE Circuits and Devices Magazine, Vol. 1, 1985, pp. 20-32

8. R. Senani, New electronically tunable OTA-C sinusoidal oscillator, Electronics Letters, Vol. 25 , 1989, pp. 286-287 

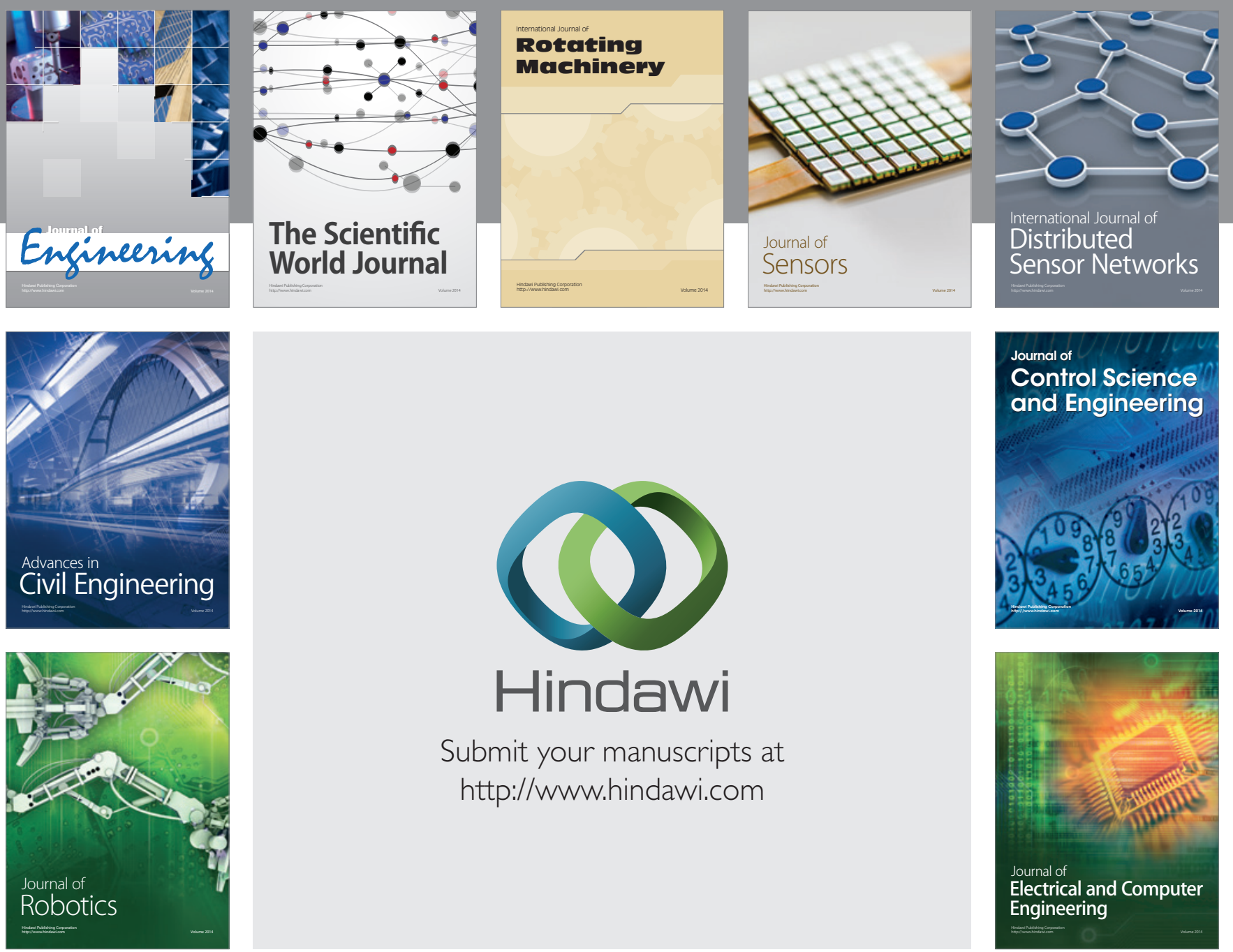

Submit your manuscripts at

http://www.hindawi.com
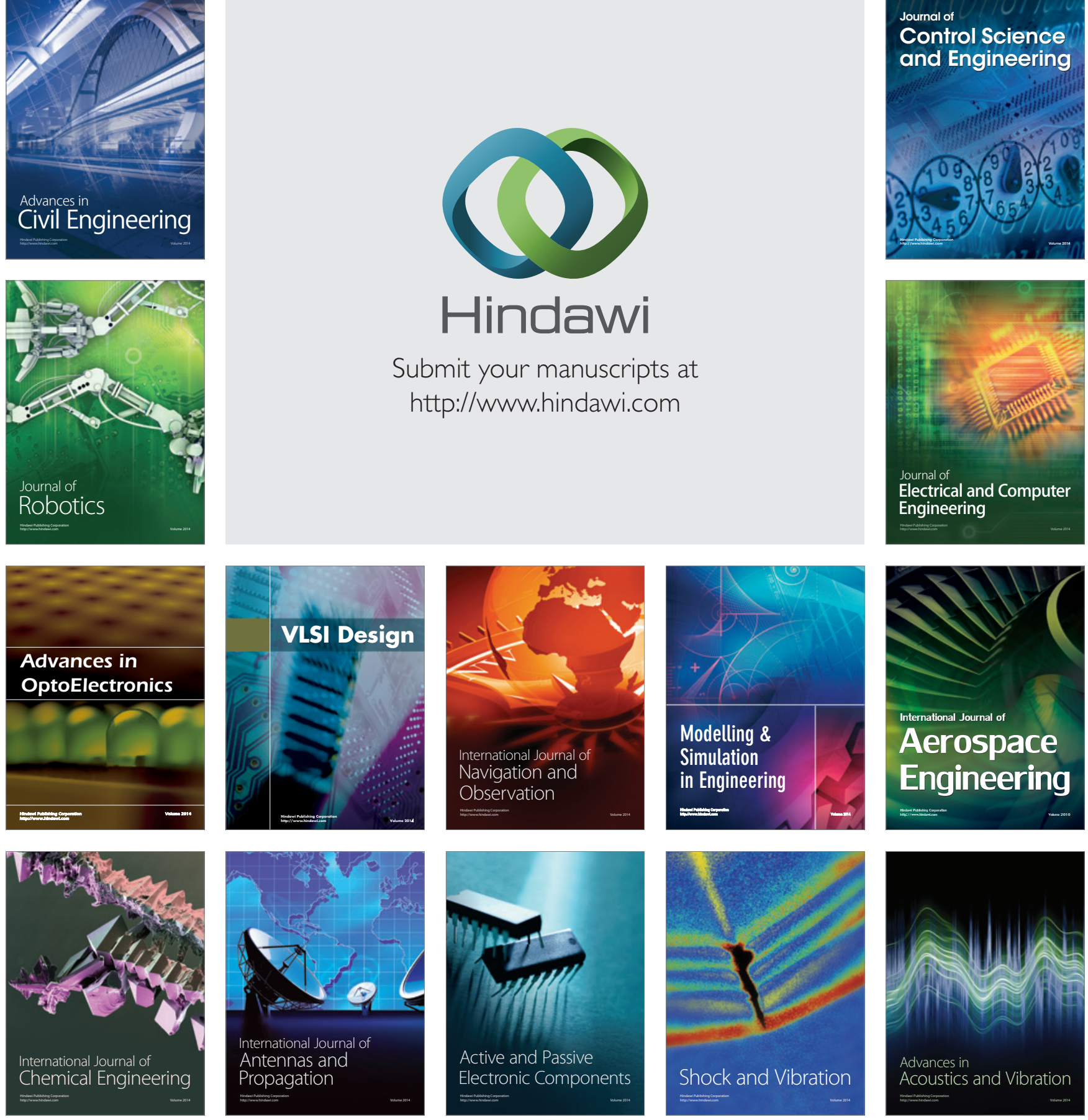